\title{
A PEDAGOGIA DO CONSUMO: ESTRATÉGIAS DA MARCA GUARANÁ ANTARCTICA $^{1}$
}

\section{Pedagogy of consumption:brand strategies of guaraná antarctica}

\author{
Priscila Azeredo da Silva ${ }^{2}$ \\ Sandro Tôrres de Azevedo ${ }^{3}$ \\ Thaiane Moreira de Oliveira ${ }^{4}$ \\ Guilherme Nery Atem ${ }^{5}$ \\ Laura Martini Bedran ${ }^{6}$ \\ Mariana Ayres Tavares ${ }^{7}$
}

\section{Resumo}

$\mathrm{O}$ artigo tem como objetivo analisar como a publicidade ensina ao consumidor modos de usar os objetos de consumo. Tal abordagem irá privilegiar as transformações ocorridas no aspecto estratégico da comunicação publicitária da marca, tangenciando questões relacionadas a experiência. Para isso, a pesquisa recorre, a título de objeto de análise, à periodização de três momentos da publicidade do Guaraná Antarctica: nos anos 1920, nos anos 1990 e nos anos 2000.

Palavras-chave: pedagogia do consumo, história da publicidade, estratégias de marca, experiência.

\footnotetext{
Abstract

The article aims to analyze how advertising teaches ways to consumer use objects of consumption. This approach will focus on the changes in the strategic aspect of the advertising communication of the mark, touching on issues related experience. For this,

${ }^{1}$ Trabalho apresentado no GP Publicidade - Marcas e Estratégias, do X Encontro dos Grupos de Pesquisa em Comunicação, evento componente do XXXIII Congresso Brasileiro de Ciências da Comunicação, em Caxias do Sul, 2010.

${ }^{2}$ Graduada em História pela UFF. Mestranda do PPGCOM da UFF.

${ }^{3}$ Mestre em Comunicação pela UFRJ-ECO. Professor da UNESA e da UVA.

${ }^{4}$ Graduada em Comunicação Social pela UNESA. Mestranda do PPGCOM da UFF.

5 Doutor em Comunicação e Cultura pela UFRJ-ECO. Professor do Departamento de Comunicação Social da UFF e do PPGCOM da UFF. Líder do Grupo de Pesquisa "Retórica do Consumo". Contatos: (21) 2621-8905 / 8870-1852. E-mail: gui.nery@ globo.com.

${ }^{6}$ Doutora em Comunicação pelo PPGCOM da UFF. Professora do Departamento de Comunicação Social da UFF.

${ }^{7}$ Graduanda e bolsista PIBIC em Publicidade, no Departamento de Comunicação Social da UFF.
} 
A pedagogia do consumo: estratégias da marca guaraná antarctica

de Priscila Azeredo da Silva, Sandro Tôrres de Azevedo, Thaiane Moreira de Oliveira,

Guilherme Nery Atem, Laura Martini Bedran e Mariana Ayres Tavares

the research uses, as an object of analysis, the periodicity of three times the advertisings of Guaraná Antarctica: in the 1920s, the 1990s and 2000s.

Keywords: pedagogy of consumption, history of advertising, brand strategies, experience.

\section{Resumen}

El artículo pretende analizar cómo la publicidad enseña a los consumidores formas de utilizar objectos de consumo. Este enfoque se centrará en los cambios en el aspecto estrategico de la comunicación publicitaria de la marca, tocando temas relacionados con la experiencia. Para ello, utiliza la investigación, como objeto de análisis, la periodicidad de tres veces la publicidad de Guaraná Antarctica: en los años 1920, 1990 y 2000.

Palabras clave: pedagogía del consumo, historia de la publicidad, estrategias de marca, experiencia.

\section{INTRODUÇÃO}

A proposta deste trabalho é discutir a relação entre a publicidade e a sociedade em três momentos distintos, a partir da ideia de pedagogia do consumo nas perspectivas estratégicas de comunicação de marcas. No primeiro momento, abordaremos a publicidade que tinha por finalidade apresentar os produtos materiais para o público consumidor. Denominada como fase material, o produto era a o foco central da peça publicitária. No segundo, apresentaremos as transformações ocorridas já na segunda metade do século XX, em que o objetivo da publicidade já não era apenas vender um produto, mas sim um conceito atrelado à marca. Por fim, encontramos um terceiro momento, no qual a publicidade retoma a ideia de materialidade, porém, esta é explorada a partir de experiências propiciadas ao seu público-alvo. Cabe ressaltar que, assim como todas as categorizações do campo epistemológico da área de Ciências Humanas, estes momentos são tipos ideais. Portanto, por serem ideais, não são categorias "puras", ou seja, ao longo da História, o surgimento de um momento não invalida o estágio anterior.

A hipótese que permeia este trabalho é de que nestes três momentos históricos da publicidade, a experiência entre a publicidade e seu público proporciona Pedagogias 
A pedagogia do consumo: estratégias da marca guaraná antarctica

de Priscila Azeredo da Silva, Sandro Tôrres de Azevedo, Thaiane Moreira de Oliveira,

Guilherme Nery Atem, Laura Martini Bedran e Mariana Ayres Tavares

de Consumo diferenciadas, contribuindo para uma transformação social na qual se altera o sentido de vida, tendo o consumo como centralidade.

Com finalidade ilustrativa, a pesquisa traz peças de campanhas publicitárias do Guaraná Antarctica que demonstram cada fase elencada. A escolha se deve ao fato de a marca ser legitimamente nacional, pertencente a uma empresa estável, fundada no início do século XX e que passou por estes três estágios, demonstrando todo o processo de adaptação estratégica da marca frente às mudanças aqui apresentadas em sua publicidade.

Para demonstrar a primeira etapa, em que a publicidade ocupava a função de informar sobre o produto a ser vendido, foi escolhida uma das primeiras peças publicitárias do Guaraná Antarctica, datada da década de 1920, na qual o produto é apresentado ao público, ensinando-o as formas de consumo através de argumentações informativas.

Com relação à segunda fase, que representa a transição do material para o imaterial dos conceitos atrelados à marca, vamos analisar uma campanha da década de 1990, fortemente marcada pelo inicio do processo de conceituação da marca como estratégia de posicionamento global, com o slogan "Este é o sabor". Com a influência do movimento de globalização, a marca ganha, estrategicamente, valores simbólicos, induzindo não mais uma apresentação do produto apenas, mas tendo como centralidade o consumo gerenciado por uma "Economia Política dos Afetos".

E, por fim, no terceiro momento, traremos à luz deste estudo o Alternate Reality Game Zona Incerta, promovido pelo Guaraná Antarctica. Esta foi uma campanha de mobilização nacional calcada na experiência e na relação aproximada com o públicoalvo. Agora, para conquistar a mente do público e ensinar a consumir, a publicidade não se utiliza apenas das informações do produto, dos apelos racionais ou da política de gerar sensações positivas, mas busca proporcionar aos consumidores um envolvimento totalizante com a marca. Nesta fase, há uma convergência tecnológica que permeia a questão da experiência na publicidade.

\section{PRIMEIRO MOMENTO: POR UM CONTEXTO DA PEDAGOGIA DO CONSUMO}


Para compreender a mudança ocorrida no século $\mathrm{XX}$, em que a ênfase da produção passa para o consumo, é preciso ter em mente que a publicidade desempenhou um papel relevante nesse processo de transformação da sociedade de produção para a sociedade de consumo (Bauman 1999: 88-89). Para tanto, faz-se necessário conhecer o contexto em que ela se insere.

Na fase industrial (aproximadamente entre os séculos XVIII e XIX) há um esforço político e cultural para a formação de trabalhadores: (a) a educação é utilizada como instrumento de disciplina útil ao universo do trabalho ${ }^{8}$; (b) surgem políticas de regulamentação da divisão espaço-temporal entre tempo-lugar de trabalho e tempolugar livre9; (c) além dos valores morais difundidos na sociedade, como a ética protestante, em que o trabalho é supervalorizado como uma forma de distinção do "bom" homem, cujo tempo deve ser bem empregado, assim como o dinheiro, marcando o consumo como uma prática negativa até o início do século XX (Thompson 1991: 6670). "Pensamos demais na produção e de menos no consumo. Por isso, acabamos dando pouca importância ao desfrute e à felicidade e deixamos de avaliar a produção pela satisfação que ela proporciona ao consumidor", diz o filósofo Bertrand Russell (2004: 32). ${ }^{10}$

Segundo Naomi Klein (2004), as raízes da publicidade que hoje conhecemos brotam na segunda metade do século XIX. Nesse período, surgiram novos produtos no mercado, os quais a população desconhecia completamente (como a lâmpada elétrica, por exemplo). As funções iniciais da publicidade eram: informar sobre os novos produtos presentes no mercado (para que serviam e como utilizá-los, por exemplo) e, ao mesmo tempo, convencer a população de que suas vidas seriam melhores se tais produtos fossem consumidos. Vejamos um anúncio do Guaraná Antarctica, exemplificando aquele momento:

\footnotetext{
${ }^{8} \mathrm{Na}$ escola, indivíduo aprende não só o conteúdo, mas a disciplina necessária para cumprir horários, metas e a respeitar hierarquias.

${ }^{9}$ Como as leis trabalhistas que regulamentaram o horário de trabalho e de descanso, por exemplo.

${ }^{10}$ O texto "Elogio ao Ócio" foi publicado em 1935 na Inglaterra e nos ajuda a compreender a forma de pensar o tempo livre, o trabalho e o consumo do início do século XX.
} 


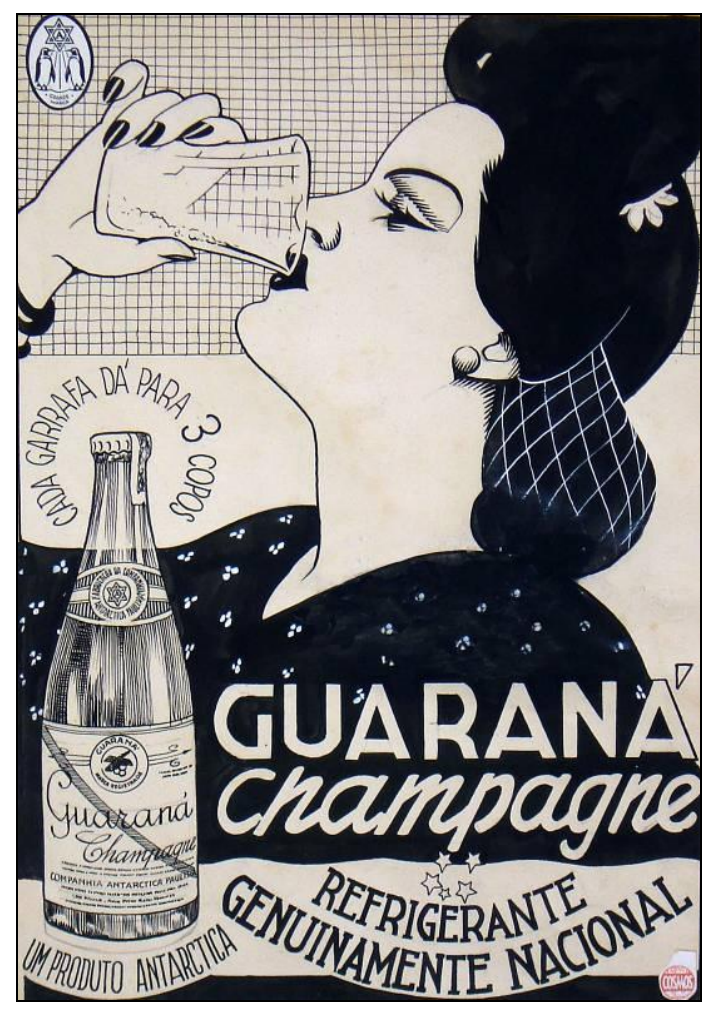

Fig. 1

Este primeiro anúncio data da década de 1920 e é veiculado em preto-e-branco. Nele vemos a ilustração de uma garota-propaganda bebendo o Guaraná Antarctica. Em primeiro plano, vemos a ilustração do produto, que é acompanhada do texto "Guaraná champagne / refrigerante genuinamente nacional". Há estrelinhas no meio desses dizeres. O anúncio é saturado de imagens, e parece pretender construir uma complementaridade entre os elementos verbal e visual.

A garota-propaganda o está bebendo num copo, o que conota mais "civilização", e logo abaixo deste lemos: "Cada garrafa dá para 3 copos". No alto à esquerda há um logo da empresa, com os dois pinguins da Antarctica. A moça está vestida com trajes da época, está maquiada e seu cabelo dá bem o "tom" de requinte. O produto parece destinar-se às classes média e alta - vide a palavra "champagne".

Como se sabe, todo discurso carrega valores ideológicos, ou seja, uma certa perspectiva fundada em uma determinada classe social. Com a marca Antarctica não seria diferente. A perspectiva de classe burguesa é evidente na figura da garotapropaganda. Ela representa o consumidor médio, não só de produtos, mas também de cultura. Ela tem bom gosto, sofisticação e, justamente por isso, toma o Guaraná Antarctica. 
Ao afirmar-se como o "refrigerante genuinamente nacional", a Antarctica, além de ensaiar uma crítica aos concorrentes - que seriam "falsamente nacionais", pelos princípios do interdiscurso (Maingueneau 2005) - afirma-se como a opção mais "natural”, mais razoável (racional) para o consumidor brasileiro.

Digno de nota, também, é a frase: "Cada garrafa dá para 3 copos". Tal recurso retórico pretende explicar mais uma vantagem (racional) do produto anunciado. Vemos a importância do produto, nas estratégias mercadológicas da década de 1920. Mas agora, vamos adiante, para alcançarmos o segundo momento.

\section{SEGUNDO MOMENTO: A PUBLICIDADE NA PASSAGEM DO MODELO MATERIAL PARA O IMATERIAL}

Com o desenvolvimento técnico, o número de trabalhadores necessários à produção foi diminuindo. O marco da transição é a Revolução Informacional, ocorrida na segunda metade do século XX, e seu processo peculiar de circulação do capital e dos serviços. Este Semiocapitalismo, imaterial, ancora-se sobre uma dominação dos conceitos, da linguagem, dos signos, mas também dos direitos, das finanças, das marcas, dos serviços - e, portanto, das subjetividades. Revela-se aí toda uma "Economia Política dos afetos e dos signos".

Em primeiro lugar, a novidade dessa atual forma de organização do Capitalismo seria a introdução fundamental dos processos avançados de informatização na produção fabril, a partir da segunda metade do século XX. A maior integração entre empresa e fábrica revela a importância do trabalho informacional (Cocco \& Galvão \& Silva 2003: 08): “À medida que a indústria se torna cada vez mais terciária, os serviços se tornam cada vez mais industriais".

É claro que as instâncias de produção e de consumo sempre se correlacionaram, mas depois da segunda metade do século XX, a sociedade passou a priorizar e enfatizar a formação do indivíduo como consumidor ${ }^{11}$. A publicidade passa, então, a desempenhar um papel pedagógico importante na formação desse indivíduo-consumidor ao incentivar e sugerir modos de consumo como equivalentes a "modos de ser"12.

\footnotetext{
${ }^{11}$ A formação do indivíduo como trabalhador passou a ocupar o segundo plano.

${ }^{12}$ A publicidade não instaura uma ditadura do consumo. Ela apenas estimula e orienta o consumidor, e este sempre terá a opção de consumir ou não.
} 
A pedagogia do consumo: estratégias da marca guaraná antarctica

de Priscila Azeredo da Silva, Sandro Tôrres de Azevedo, Thaiane Moreira de Oliveira,

Guilherme Nery Atem, Laura Martini Bedran e Mariana Ayres Tavares

Nesse sentido, falar de uma pedagogia do consumo implica reconhecer que a publicidade contribuiu com as inovações tecnológicas industriais, para transformar o modo como as pessoas viviam, seja por inserir no cotidiano elementos e modos de consumo que modificaram os hábitos e costumes da sociedade (como a inserção da lâmpada elétrica nas casas e a alteração na rotina do sono, ou a inserção do refrigerador e as mudanças nos hábitos alimentares), seja por colaborar na formação de um novo sentido de vida em que o consumo ganha a centralidade.

Vale ressaltar que a plena negociação dos pares, produção-recepção, é fundamental para a pedagogia do consumo. Mas esse "diálogo" só é efetivamente determinado quando o contexto geral comparece e se evidencia. Segundo Bauman (2008), a sociedade contemporânea experimenta uma "cultura consumista", que, sinteticamente, envolve velocidade, excesso e desperdício. Um ambiente de efemeridades, onde as promessas do marketing e da publicidade se transformam em satisfações passageiras. É nessa circunstância (contexto geral) em que:

Consumidores plenos não ficam melindrados por destinarem algo para o lixo (...). Como regra, aceitam a vida curta das coisas e sua morte predeterminada com equanimidade, munitas vezes com um prazer disfarçado, mas às vezes com a alegria contida da comemoração de uma vitória. (Bauman 2008: 112)

Naomi Klein (2004: 30-31) constata que, nesta segunda metade do século XX, a publicidade passa por uma transformação. Além de informar e incitar a compra, ela deveria construir peças publicitárias cheias de "significados" capazes de transmitir "sensações positivas" aos seus consumidores. O objetivo desta nova lógica era driblar a concorrência e minimizar a imagem pejorativa do consumo ${ }^{13}$. O resultado desta estratégia foi uma maior aproximação com o consumidor e, aparentemente, o aumento das vendas, o que levou as corporações a aumentarem lentamente os seus investimentos em publicidade, ao mesmo tempo em que buscavam reduzir os custos da produção, especialmente com a mão-de-obra.

Nesse aspecto há também que se considerar a ampliação dos diálogos acumulados entre público leitor e mensagens através de um "alfabetismo visual" conforme definição de Dondis:

\footnotetext{
${ }^{13} \mathrm{O}$ consumo era interpretado como uma prática fútil.
} 
A pedagogia do consumo: estratégias da marca guaraná antarctica

de Priscila Azeredo da Silva, Sandro Tôrres de Azevedo, Thaiane Moreira de Oliveira,

Guilherme Nery Atem, Laura Martini Bedran e Mariana Ayres Tavares

Ao final de um longo período de envolvimento com os elementos visuais e exposição aos mesmos, os resultados deveriam refletir o que significa termos aprendido todo o alfabeto. É preciso que haja uma grande familiaridade com os elementos visuais. Precisamos conhecê-los 'de cor'. Em outras palavras, seu reconhecimento ou sua utilização deve alçar-se a um nível mais alto de reconhecimento que os incorpore tanto à mente consciente quanto à inconsciente, para que o acesso até eles seja praticamente automático. Devem estar ali, mas não de modo forçado; devem ser percebidos, mas não soletrados, como acontece com os leitores principiantes. (Dondis 1991: 228).

O termo apresentado pelo autor expande-se do produtor de mensagens ao receptor. As imagens projetadas no intenso fluxo das diversas comunicações fornecem, muitas vezes, apenas uma pequena parte da informação e nem por isso tornam-se incompletas para sua compreensão. Como uma pedagogia do consumo e do olhar, o leitor busca completar a informação através de seu repertório interno. Ao longo de décadas de informações e imagens que se acumulam, o grande repertório que já pertence ao indivíduo, principalmente dos grandes centros urbanos, entra em jogo e aumenta a capacidade de diálogo entre a mensagem publicitária e o público leitor.

Já no princípio da década de 1990, a linguagem da propaganda mudou com os avanços da informática e da economia global. Produtos importados chamando os nacionais à competição; fusões de empresas para fortalecimento do mercado interno; estruturas corporativas mais enxutas; a segmentação dos veículos de comunicação como uma forte tendência - cada vez mais se buscam respostas individuais para a ampliação do público. TV por assinatura, serviços on-line, marketing direto.

A década de 1990 iniciou o processo de informatização em que hoje estamos imersos. Foram transformações tecnológicas que migraram para o campo cultural. Neste período, a publicidade tornou-se mais ambiciosa, principalmente no que se refere às marcas. Segundo Klein, "o que torna diferente o branding dos anos 90 é que ele cada vez mais procura retirar essas associações do reino da representação e transformá-las em uma realidade da vida" (Klein 2004: 53). Para isso, a publicidade propõe às grandes marcas que suas "imagens" vendam um "conceito" e não um "bem material". Afinal, o "bem material" em si pode ser copiado, mas a "imagem" 14 produzida pela publicidade, não.

Cada vez mais o que se consome são serviços, tecnologias informáticas e comunicacionais e os conteúdos informacionais, culturais, artísticos intimamente

\footnotetext{
${ }^{14}$ Martine Joly define imagem como "(...) operações mentais, individuais, ou coletivas que (...) insistem mais no aspecto construtivo e identitário da representação do que em seu aspecto visual de semelhança." (JOLY, 1996, p.21)
} 
A pedagogia do consumo: estratégias da marca guaraná antarctica

de Priscila Azeredo da Silva, Sandro Tôrres de Azevedo, Thaiane Moreira de Oliveira,

Guilherme Nery Atem, Laura Martini Bedran e Mariana Ayres Tavares

associados à ferramenta, cuja especificidade repousa justamente na indissociabilidade dos conteúdos que ela veicula” (Corsani, In: Cocco \& Galvão \& Silva 2003: 25).

A economia do imaterial é toda baseada na produção, reprodução e circulação de informações. Na verdade, a empresa não produz qualquer "objeto concreto". O que ela produz são signos: conceitos, idéias, afetos, serviços, fidelidades, marcas, notícias, etc. Segundo Maurizio Lazzarato e Antonio Negri, os serviços são como os produtos, só que imateriais.

A 'necessidade de consumir, a capacidade de consumir, a pulsão de consumir' não são mais produzidas indiretamente pelo objeto (produto), mas diretamente por dispositivos específicos que tendem a identificar-se com o processo de constituição da 'comunicação social'. A publicidade e a produção da 'capacidade de consumir, do impulso ao consumo, da necessidade de consumir', transformaram-se num 'processo de trabalho' (Lazzarato \& Negri 2001: 46).

Este trabalho dos publicitários é tipicamente imaterial, pois que lida com imagens, conceitos, desejos, impulsos, sonhos, esperanças; lida diretamente com signos que carregam os afetos do consumo. No Capitalismo industrial, o valor de um produto material era medido, entre outros fatores, pela sua raridade: a posse daquele objeto ligava-o ao conceito de propriedade. Já neste Capitalismo Semiótico, o valor de uma informação se mede pela sua capacidade de compartilhamento - ou seja, quanto mais a informação tiver potência de circulação, mais valor ela terá ${ }^{15}$. Vejamos um anúncio do Guaraná Antarctica, da década de 1990:

15 Um bom exemplo disso é o conceito de "memes", em Marketing e Publicidade - tema que exploraremos mais adiante. O franchising segue a mesma lógica expansionista. 


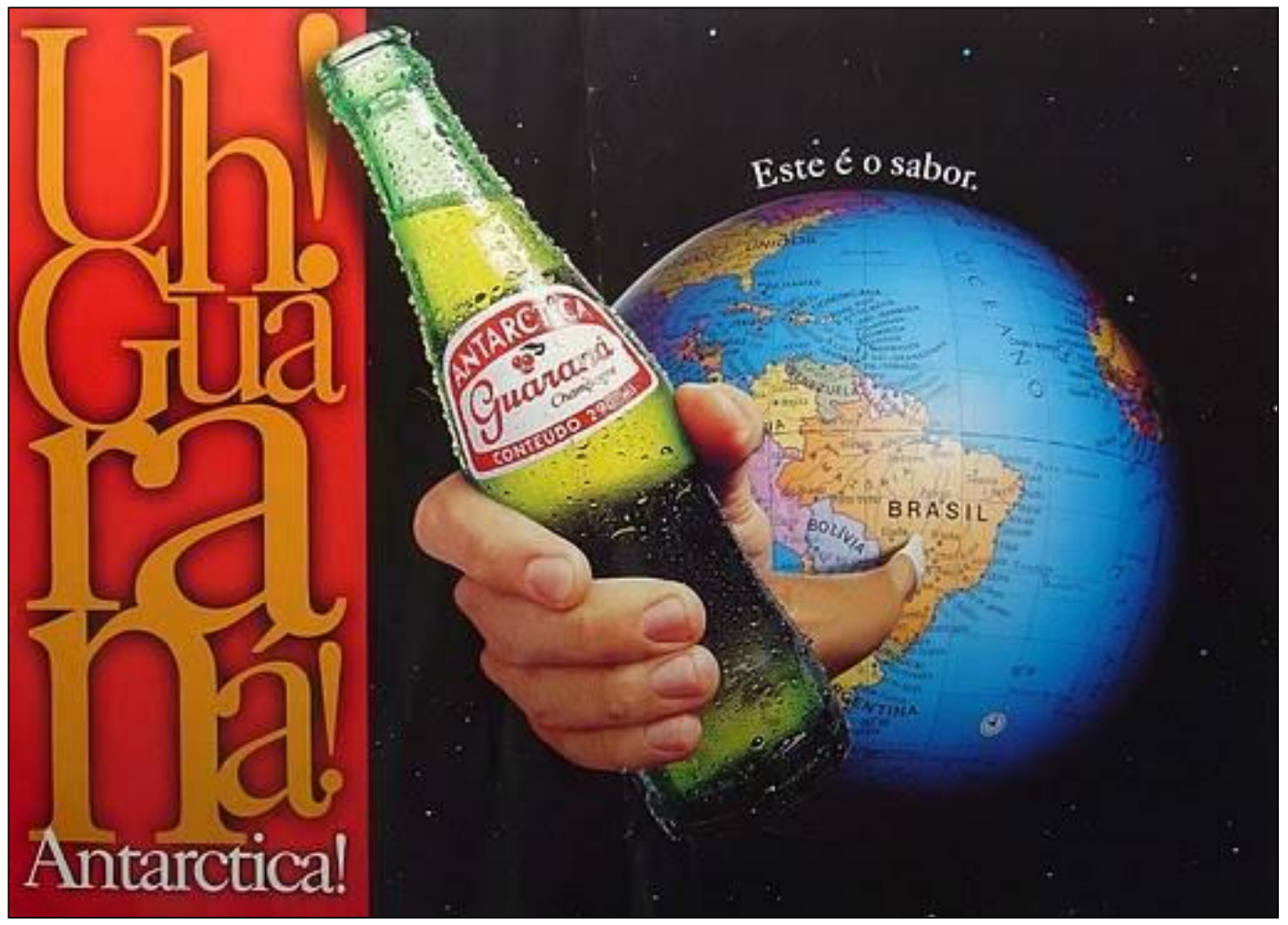

Fig. 2

Diferente do anúncio do primeiro momento, este utiliza as cores como um elemento de destaque. À esquerda, vemos um título-texto dizendo: "Uh! Guaraná! Antarctica!". Notam-se três exclamações seguidas, numa tentativa de apoiar a comunicação da marca na função fática (Jakobson s/d.). O nome da marca aparece em branco, porque deve distinguir-se, enquanto a frase anterior, em amarelo. O espaço maior, à direita, traz a imagem de um globo terrestre boiando no espaço - como se a sensação de "deriva existencial" fosse compensada pela garantia de "sabor" do refrigerante.

Do centro do território brasileiro, no mapa redondo, sai um braço estendido, empunhando vigorosamente uma garrafa de Guaraná Antarctica - que está aberta e molhada de tão gelada. A brasilidade da marca é afirmada categoricamente, agora não por palavras (logos; apelo racional), mas pela imagem (pathos; apelo emocional), contundente, do Guaraná Antarctica saindo do Brasil para ganhar o mundo.

Acima do globo, a frase-slogan: "Este é o sabor". Esta frase-slogan pretende resumir o conceito que a marca constrói para si: “o sabor” é algo que pertence ao 
A pedagogia do consumo: estratégias da marca guaraná antarctica

de Priscila Azeredo da Silva, Sandro Tôrres de Azevedo, Thaiane Moreira de Oliveira,

Guilherme Nery Atem, Laura Martini Bedran e Mariana Ayres Tavares

Guaraná Antarctica, e somente a ele. Algo de "genuíno" se mantém, em referência ao primeiro momento, analisado anteriormente.

O Guaraná Antarctica mantém e reforça nesta peça todo o seu conceito em torno de sua originalidade e nacionalidade (brasilidade). E amplia seu posicionamento uma vez que os elementos visuais e o texto se complementam para gerar o sentido desejado. O globo traz para o anúncio um novo âmbito de abordagem, levando o Guaraná para o mundo. Isso pontua a estratégia da empresa de tornar a marca conhecida em escala mundial. A busca de um sentido ampliado é feita através da mescla entre imagem e texto, primeiro com o titulo "Este é o sabor" alusão ao Guaraná Antarctica que esta saindo do Mapa na localização do Brasil, então este é o sabor do Brasil para o mundo, por que este foi representado pela imagem do Globo.

\section{TERCEIRO MOMENTO: A PUBLICIDADE COMO MEDIADORA DE EXPERIÊNCIAS}

A publicidade nasceu para informar, mas há muito essa função básica foi extrapolada. Sem atentar muito para evolução, ao longo dos anos, a publicidade se apresenta como parte da vida dos consumidores, vendendo não mais um produto e sim um estilo de vida, uma personalidade. Em um cenário onde concorrentes se multiplicam e o mercado consumidor diminui, faz-se necessário ir além dos aspectos físicos do produto, a subjetividade ganha o cenário onde o script da vida é dado para o público.

Na sociedade ocidental contemporânea a estrutura da comunicação passou a desenvolver uma outra concepção. Passou a se encarregar de uma nova produção de identidade no indivíduo enquanto indivíduo e nele enquanto pertencente à sociedade, não mais pertencente à mesma lógica passiva proveniente das configurações geradas pelos meios de comunicação de massa. Na atualidade, a lógica que rege é a da convergência tecnológica, social e cultural. Através desta lógica, não apenas convergências de suportes midiáticos que estão sendo estruturados, mas também convergem o "comportamento migratório dos públicos dos meios de comunicação, que vão a quase qualquer parte em busca das experiências de entretenimento que desejam." (Jenkins 2005: 27). Ou seja, a convergência envolve uma transformação não apenas das formas de produção dos meios, como também, nas mais diversas formas de consumir através destes mesmos meios. 
A pedagogia do consumo: estratégias da marca guaraná antarctica

de Priscila Azeredo da Silva, Sandro Tôrres de Azevedo, Thaiane Moreira de Oliveira,

Guilherme Nery Atem, Laura Martini Bedran e Mariana Ayres Tavares

Esta lógica faz parte de uma transformação cultural que tem sido explorada pelo mercado publicitário nas mais diversas estratégias baseadas em experiências participativas. Desta forma, a publicidade atual não busca apenas divulgar sua marca, mas também estar no Top of Mind dos consumidores, através de uma relação afetiva calcada pela experiência de envolvimento totalizado do consumidor com o produto, como afirma Baudrillard.

Chegamos ao ponto em que o consumo invade toda a vida, em que todas as atividades
se encadeiam do mesmo modo combinatório, em que o canal das satisfaçóes se
encontra previamente traçado, hora a hora, em que o envolvimento é total,
inteiramente climatizado, organizado, culturalizado. (Baudrillard 2005: 19 - grifos do
autor).

Para o autor, vivemos em uma sociedade de consumo, através da qual nossos desejos e afetos são pautados pelo simbólico e calcados nesta relação não apenas entre os objetos e os sujeitos/consumidores, mas também entre a coletividade e o mundo (Baudrillard 1993). Apesar de focar sobre representações simbólicas do consumo através de uma lógica da não-presencialidade, é possível observar que Baudrillard cristaliza este momento atual no qual o consumo está inserido nas relações sociais através de um envolvimento total. Porém, é possível ainda perceber uma mudança brusca nesta relação entre as mensagens publicitárias e seus públicos. As práticas publicitárias atuais buscam enquadrar os desejos e afetos através de proporcionamento inovador de vivências tangíveis ao envolvimento desta nova ordem de consumidores, que já não aceita imperativos publicitários, mas prioriza o consumo de experiências reais (mesmo que artificiais, em sua natureza).

Karl Ludwig Pfeiffer, em obra conjunta com Gumbrecht, afirma que o ato da comunicação deve ser visto "menos como uma troca de significados, de ideia sobre (algo), e mais como uma performance posta em movimento por meio de vários significantes materializados" (Pfeiffer 1994: 6). E o que circunda os aspectos da publicidade contemporânea é a consequente experiência com a marca, que acompanha uma tendência cada vez mais sensorial. Sendo assim, em um jogo para ganhar a mente do consumidor, num mundo de marcas e informações, ensinar a consumir não é mais informar atributos físicos e racionais. É proporcionar ao seu público um envolvimento totalizado pela experiência. 
A pedagogia do consumo: estratégias da marca guaraná antarctica

de Priscila Azeredo da Silva, Sandro Tôrres de Azevedo, Thaiane Moreira de Oliveira,

Guilherme Nery Atem, Laura Martini Bedran e Mariana Ayres Tavares

É possível perceber este momento da publicidade em diversas estratégias de posicionamento da marca que trabalham a convergência tecnológica proporcionando experiências a seu público consumidor. Estratégias que vão desde o uso de Realidade Aumentada à advergames e jogos pervasivos ${ }^{16}$, através de formas camufladas de "marketing oculto que faz malabarismos para tentar contornar a fadiga, desenvolvendo técnicas de comunicação que apresentam o produto de maneira inusitada, a fím de evitar que o público-alvo perceba tratar-se de uma abordagem mercadológica convencional". (Moraes 2006: 43). Para compreensão deste momento, este trabalho apresentará o Alternate Reality Game Zona Incerta, produzido pelo Núcleo Jovem da Editora Abril em parceria com a Ambev, para promover o Guaraná Antártica, em 2007.

Os Alternate Reality Games - ou Jogos de Realidade Alternada - são um gênero de jogo que transcende a realidade e a ficcionalidade através de enigmas que ocupam tanto os espaços virtuais, como também, os espaços urbanos. Originados da experiência do Role Playing Games, os Alternate Reality Games são considerados uma subcategoria dos jogos pervasivos. Neste gênero de jogo que têm como pano de fundo uma narrativa multilinear complexificada, os jogadores são instigados a desvendar enigmas propostos por um personagem real, envolto em uma narrativa de mistério capaz de gerir a imersividade, metáfora derivada da experiência física de submergir na água e ficar envolvido por uma realidade diferente (Murray 2003: 97-99).

Geralmente, os ARGs se iniciam com um pedido de ajuda na internet, chamado como Rabbit Hole pela comunidade gamer, uma expressão utilizada em alusão ao livro Alice in Wonderland de Lewis Carrol, para indicar a estratégia utilizada pelos produtores (puppetmasters ${ }^{17}$ ), para fisgar o seu público-alvo e levá-los à imersividade no game de uma maneira em que a realidade e a ficcionalidade se tornam fluidas. No desenrolar da narrativa diversos enigmas, dos mais simples aos mais complexos, vão sendo apresentados aos jogadores que utilizam o preceito de Inteligência Coletiva (Lévy 1999) e compartilham dúvidas e descobertas com os outros jogadores nas comunidades de redes sociais para assim dar continuidade ao jogo.

\footnotetext{
16 Jogo pervasivo, também chamado de ubíquo, é um gênero de game que busca transcender suas ações para além do suporte material mediador entre o jogador e o programa, explorando além dos espaços virtuais eletrônicos, os espaços físicos urbanos da realidade concreta.

17 Termo utilizado para referenciar os produtores deste gênero de game, em alusão aos titereiros de fantoches..
} 
A pedagogia do consumo: estratégias da marca guaraná antarctica

de Priscila Azeredo da Silva, Sandro Tôrres de Azevedo, Thaiane Moreira de Oliveira,

Guilherme Nery Atem, Laura Martini Bedran e Mariana Ayres Tavares

O Alternate Reality Game Zona Incerta teve a participação de mais de 70 mil jogadores em todo o país e produziu diversos live actions que proporcionaram uma experiência totalizada a estes participantes, em busca de pistas e de 42 garrafas antigas de Guaraná Antártica espalhadas em várias cidades do país. Neste game, foi possível perceber a transição entre realidades e ficcionalidades em diversos momentos, porém o mais polêmico foi quando o senador Arthur Virgílio (PSDB/AM), no dia 29 de maio de $2007^{18}$, denunciou a fictícia empresa Arkhos Biotech que se propunha privatizar a Amazônia, sem saber que a mesma fazia parte deste jogo ${ }^{19}$.

A partir desses exemplos é possível verificar que a publicidade está direcionando sua pedagogia do consumo para a questão da experiência, valendo-se de estratégias ligadas a atividades culturais e de lazer para produzir o registro da marca na memória do indivíduo-consumidor, não apenas como um produto, mas como um elemento integrante de uma vivência ${ }^{20}$.

\section{CONCLUSÕES}

Hoje, a marca é central no processo de pedagogia do consumo contemporâneo. Segundo Semprini (2006), como todo elemento semiótico, a marca é um resultante de contínuas trocas e negociações que particularmente implicam três atores: um pólo de produção, que envolve um aglomerado de instâncias que vão da empresa que detém a marca, o trabalho de marketing, comunicação e publicidade, entre outros que contribuem para envolver a marca num universo de códigos; um pólo de recepção, que não se limita ao público-alvo da marca, mas amealha ainda um espectro mais amplo da sociedade, sobre o qual a significação da marca é tão importante quanto é para o público-alvo; e um pólo que se traduz como contexto geral, que pode ser entendido como o cenário atuante, onde se dá o processo de produção-recepção e que é inseparável dessa sistemática de negociação.

Ao longo do período analisado, é possível perceber que a mensagem publicitária assumiu uma função didática, que "ensina" qual percepção deve se anelar à marca e

${ }^{18}$ Este dia ficou conhecido pela comunidade gamer como o Dia Nacional do ARG.

19 A fictícia empresa Arkhos Biotech, utilizava um discurso baseado em uma retórica persuasiva e documental, o que se assemelha à realidade, fez com que milhares de brasileiros acreditassem na veracidade do vídeo. http://www.youtube.com/watch?v=WAg79cU2s7Q.

20 Para mais informações sobre o Alternate Reality Game Zona Incerta: http://www.youtube.com/watch?v=lzGm3KfcnDY. 
A pedagogia do consumo: estratégias da marca guaraná antarctica

de Priscila Azeredo da Silva, Sandro Tôrres de Azevedo, Thaiane Moreira de Oliveira,

Guilherme Nery Atem, Laura Martini Bedran e Mariana Ayres Tavares

quais são as possibilidades de manipulação simbólica oferecidas ao consumidorreceptor.

O conhecimento se torna importante: conhecimento dos novos bens, seu valor social e cultural, e como usá-los de maneira adequada. Esse é, especificamente, o caso dos grupos de aspirantes, que adotam uma atitude de aprendizes perante o consumo e procuram desenvolver um estilo de vida (Semprini 2006: 38).

Esse indivíduo multissensorial contemporâneo é exatamente carente de acoplar em si sempre novos acessórios simbólicos, pois que "um fluxo constantemente renovado de mercadorias torna mais complexo o problema da leitura do status ou da posição hierárquica do portador das mercadorias" (Featherstone 1995: 36).

O modo de consumo analisado por Featherstone desemboca precisamente neste ponto: o consumidor é aquele que precisa usar as mercadorias para delimitar as fronteiras de suas relações com os outros. Destarte, esse consumidor precisa aprender sempre novas formas de se munir de artifícios significativos para, enfim, se autoclassificar perante o meio em que transita e a publicidade oferece esse elemento através da sua pedagogia do consumo.

\section{REFERÊNCIAS BIBLIOGRÁFICAS}

BAUDRILLARD, J. A sociedade de consumo. Lisboa, Edições 70, 2005. . O sistema dos objetos. São Paulo, Perspectiva, 1993.

BAUMAN, Z. Globalização: as conseqüências humanas. Rio de Janeiro, Jorge Zahar Editor, 1999.

- Vida para consumo: a transformação das pessoas em mercadorias. Rio de Janeiro, Jorge Zahar Editor, 2008.

COCCO, G.; GAlvãO, A. P.; SILVA, G. (orgs.). Capitalismo cognitivo. Rio de Janeiro, DP\&A, 2003.

DONDIS, Donis A. Sintaxe da linguagem visual. São Paulo, Martins Fontes, 1991.

FEATERSTONE, M. Cultura de consumo e pós-modernismo. São Paulo, Studio Nobel, 1995.

JENKINS, H. Convergence culture: where old and new media collide. New York, New York University Press, 2006. 
A pedagogia do consumo: estratégias da marca guaraná antarctica

de Priscila Azeredo da Silva, Sandro Tôrres de Azevedo, Thaiane Moreira de Oliveira,

Guilherme Nery Atem, Laura Martini Bedran e Mariana Ayres Tavares

KLEIN, N. Sem logo: a tirania das marcas em um planeta vendido. Rio de Janeiro, Record, 2004.

LAZZARATO, M.; NEGRI, A. Trabalho imaterial. Rio de Janeiro, DP\&A, 2001.

LEVY, Pierre. A Inteligência Coletiva: por uma Antropologia do Ciberespaço. São Paulo, Loyola, 1999.

JAKOBSON, R. Lingüística e comunicação. São Paulo, Cultrix, s/d.

MAINGUENEAU, D. Gênese dos discursos. Curitiba, Criar, 2005.

MORAES, Dênis de. A Sociedade Midiatizada. Rio de Janeiro, Mauad, 2006.

MURRAY, J. Hamlet no Holodeck: o futuro da narrativa no ciberespaço. São Paulo, Itaú Cultural / UNESP, 2003.

PFEIFFER, K. L. "The materiality of communication", in GUMBRECHT, H. U.; PFEIFFER, K.L (orgs.). Materialities of communication. Stanford, California, Standord University Press, 1994.

RUSSELL, B. Elogio ao Ócio. Rio de Janeiro, Sextante, 2002.

SEMPRINI, A. A marca pós-moderna: poder e fragilidade da marca na sociedade contemporânea. São Paulo, Estação das Letras, 2006.

THOMPSON, E. P. "O tempo, a disciplina do trabalho e o capitalismo industrial”, in

SILVA, T. T. (org.). Trabalho, Educação e Prática social. Porto Alegre, 1991.

ARKHOS BIOTECH. <http://www.youtube.com/watch?v=WAg79cU2s7Q>.

ARG ZONA INCERTA. <http://www.youtube.com/watch?v=lzGm3KfcnDY> .

Artigo recebido: $27 / 7 / 10$

Artigo aprovado: 1/11/10 